\title{
ALIMENTOS COMERCIALIZADOS POR AMBULANTES: UMA QUESTÃO DE SEGURANÇA ALIMENTAR
}

\author{
NOURISHMENTS SOLD BY AMBULANT: A QUESTION \\ OF ALIMENTARY SAFETY
}

\author{
Carolina Mallon', Eliana Aparecida Fagundes Queiroz Bortolozo ${ }^{1^{*}}$ \\ $1^{*}$ Autor para contato: Centro Federal de Educação Tecnológica do Paraná - CEFET-PR, \\ Ponta Grossa, PR, Brasil; (42) 3220-4810; e-mail: bortolozo@pg.cefetpr.br
}

Recebido para publicação em 10/02/2005

Aceito para publicação em 15/04/2005

\section{RESUMO}

A preocupação com a segurança alimentar vem crescendo nos últimos anos, gerando uma série de discussões entre organizações governamentais, instituições de ensino e indústrias alimentícias, sobre programas que assegurem à população o acesso a produtos que não sejam prejudiciais à saúde. Sendo assim, a venda de alimentos comercializados por ambulantes representa riscos à saúde da população, em virtude da condição sanitária dos produtos comercializados. Este estudo teve como objetivo avaliar as condições higiênico-sanitárias de pontos de venda que comercializam produtos alimentícios na rua. Foram avaliados vinte e quatro pontos de venda, situados na região central do município de Ponta Grossa, Estado do Paraná. Como metodologia, utilizou-se de uma “Ficha de verificação”, elaborada segundo modelo da Vigilância Sanitária. Os aspectos considerados incluíram condições da infra-estrutura, equipamentos e utensílios, manipuladores e produção do alimento. Com base nos conceitos a pesquisa revelou os seguintes resultados: Infra-estrutura - 20,8\% péssimo, 70,8\% ruim e 8,4\% regular; Equipamentos e utensílios - 45,8\% ruim, 12,5\% regular e 41,4\% bom; Manipuladores - 16,7\% péssimo, 70,8\% ruim e 12,5\% regular; Produção do alimento - 41,7\% ruim, $41,7 \%$ regular e $16,6 \%$ bom. Quanto às condições gerais dos pontos de venda, os valores encontrados foram: $75 \%$ ruim, 20,8\% regular e 4,2\% bom, não se constatando pontuação para a classificação excelente. Sugere-se a adoção de medidas que contribuam, num primeiro momento, para o desenvolvimento de ações educativas, junto a vendedores e comerciantes, de modo a minimizar os erros e riscos identificados.

Palavras-chave: segurança alimentar; controle de qualidade de alimentos; análise de alimentos 


\begin{abstract}
Concern about safe nourishment has increased in recent years. Governmental organizations, educational institutions and food industries have been debating about programs capable of ensuring public access to safe alimentary products. For this reason, the commercialization of food by street vendors called our attention, because this practice can be harmful to people's health due to the poor sanitary conditions in which food is usually prepared and handled. Thus, the aim of this study was to evaluate the hygienic conditions of these vendors'stands. Twentyfour vending stands were evaluated in Ponta Grossa, Paraná, all of them located in the downtown area. A questionnaire based on a model developed by the "Vigilância Sanitária” was used. The survey included aspects such as infrastructure, equipment and utensils, handlers and food preparation. The results obtained were the following: infrastructure $-20.8 \%$ very bad, $70.8 \%$ bad, $8.4 \%$ regular; equipment and utensils $-45.8 \%$ bad, $12.5 \%$ regular and $41.4 \%$ good; handlers $-16.7 \%$ very bad, $70.8 \%$ bad and $12.5 \%$ regular; food preparation $-41.7 \%$ bad, $41.7 \%$ regular and $16.6 \%$ good. In relation to the general conditions of the feeding points the results were: $75 \%$ bad, $20.8 \%$ regular and $4.2 \%$ good. None of the items ranked excellent. We thus suggest the adoption of educational programs for street vendors in order to minimize the identified risks.
\end{abstract}

Key words: alimentary security; food quality control; food analysis

\section{Introdução}

A preocupação com a segurança alimentar vem crescendo nos útimos anos, gerando uma série de discussões entre organizações governamentais, instituições de ensino e indústrias alimentícias sobre programas que assegurem à população produtos que não sejam prejudiciais à saúde. Essa questão, que a princípio envolvia basicamente a disponibilidade e possibilidade de acesso da população ao alimento, está sendo discutida também em função dos riscos causados por esses mesmos alimentos (Rodrigues et al., 2003).

Por outro lado, tem crescido o interesse do público em relação à segurança alimentar, devido ao aumento do número de doenças transmitidas por alimentos. A expressão “alimentos seguros” pode ser interpretada de várias maneiras. As diferentes definições, entretanto, são dadas essencialmente a partir do que constitui um risco ou perigo significativo (Forsythe, 2002; Richards, 2002).

A segurança alimentar depende do controle exercido sobre os perigos químicos, físicos e biológicos, os quais permeiam todas as etapas da cadeia alimentar, iniciada na produção e finalizada no consumo. O trabalho a ser desenvolvido na cadeia alimentar é entendido como um processo, sendo que qualidade do resultado corresponderá à qualidade dos elementos e fatores envolvidos (Richards, 2002).

As autoridades da área de proteção dos alimentos classificam a contaminação de natureza biológica de origem microbiana como o perigo principal para a Saúde Pública (Câmara, 2002). Na classe de perigos biológicos, podem ser admitidos os macrobiológicos e os microbiológicos. Dentre os perigos macrobiológicos, citem-se, por exemplo, as moscas, mosquitos e outros insetos que, embora repugnantes, quando presentes no alimento nem sempre a sua ingestão representa risco à saúde do consumidor, salvo as poucas exceções de insetos que são venenosos. Entretanto, as patas, as asas e pêlos dos insetos podem carrear outro tipo de perigo, que são os microrganismos (perigos microbiológicos) e, dentre estes, contam-se os que são patogênicos. Por isso, os insetos representam perigos sérios, ao pousarem sobre alimentos prontos para consumo, podendo 
contaminá-los com Salmonella sp. ou Escherichia. coli entero-hemorrágica, por exemplo. Mas, caso o inseto contamine $\mathrm{o}$ alimento antes deste ser tratado termicamente, não representará um perigo importante, visto que este tratamento reduzirá o risco de dano à saúde (Chaves, 2004).

A capacidade de crescimento e de sobrevivência dos microrganismos patogênicos nos alimentos depende, não somente das características físicas e nutricionais desses alimentos, como também de um conjunto de fatores extrínsecos e intrínsecos aos mesmos, tais como: temperatura, $\mathrm{pH}$, atividade da água e potencial redox, cada um dos quais pode ser manipulado convenientemente, de modo a impedir a contaminação e o crescimento de microrganismos patogênicos (Pinto, 1996).

Os principais tipos de microrganismos causadores de doenças de origem alimentar são: Clostridium botulinum, Clostridium perfringens, Staphylococcus aureus, Bacillus cereus, Salmonella sp., Shigella sp., Campylobacter jejuni, Escherichia coli (E. coli enteropatogênica, E. coli enteroinvasora, E. coli enterotoxigênica, E. coli entero-hemorrágica), Yersínia enterocolítica, Vibrio cholerae, Vibrio parahaemolyticus eListeria monocytogenes (Franco e Landgraf, 2002).

Apesar da evolução tecnológica das últimas décadas, quanto às técnicas de conservação e higiene dos alimentos, as doenças por eles transmitidas têm sido consideradas como um grave problema de saúde pública em escala mundial, sendo os alimentos reconhecidos como o principal vetor das enfermidades entéricas agudas (Oliveira et al., 2003).

Pesquisadores calculam que aproximadamente 100 milhões de indivíduos, considerando-se a população de todos os países industrializados, contraem doenças decorrentes de alimentação inadequada, através do consumo de refeições e água contaminadas. O que causa maior espanto é que, estatisticamente, $85 \%$ dos casos poderiam ser evitados, simplesmente se as pessoas manipulassem corretamente os alimentos (Figueiredo, 2004).

O comércio de alimentos em vias públicas tem recebido, atualmente, grande atenção das autoridades e organizações internacionais, que concentram esforços na análise dos impactos econômicos, sociais e sanitários dessa atividade (Brito et al., 2003). Em contraponto, esse tipo de comércio ainda constitui risco à saúde da população, já que os produtos comercializados podem ser facilmente contaminados com microrganismos patogênicos, devido às condições inadequadas do local de preparo e à falta de conhecimento sobre técnicas de manipulação higiênica por parte dos comerciantes. Além disso, muitos estabelecimentos de comércio ambulante não contam com sistema de abastecimento de água tratada, o que dificulta a higienização correta dos utensílios utilizados no preparo das refeições (Rodrigues et al., 2003).

Entende-se por alimentos comercializados por ambulantes, alimentos e bebidas prontos para o consumo, preparados e/ou vendidos nas ruas e outros lugares públicos similares, para consumo imediato ou posterior, sem que haja, contudo, etapas adicionais de preparo ou processamento. Nesta definição também são incluídas as frutas frescas e vegetais vendidos fora das áreas comerciais autorizadas (Cardoso et al., 2003).

Geralmente, as áreas de venda apresentam infraestrutura inadequada, falta de acesso a água potável e a instalações sanitárias, o que faz aumentar os riscos de servirem como veículos de doenças. Os alimentos de rua, em geral, são caracterizados pelo baixo preço, familiaridade, conveniência e fácil acesso. Sua oferta varia conforme ariqueza cultural da população (Hanashiro et al., 2002).

Fiscalizar e controlar o comércio informal de alimentos parece ser a meta mais fácil de se alcançar. Acabar definitivamente com eleé impossível, posto que implicaria fatores de ordem econômica a serem contornados, além de mudança na mentalidade da população consumidora. O seu controle pode ser melhorado, através de uma legislação mais racional - nem muito branda em certos aspectos, nem rigorosa demais em outros - e, principalmente, por meio de uma política fiscal mais equilibrada e condizente com a realidade. Os serviços municipais de fiscalização deveriam ser aplicados com sentido mais educativo do que fiscalizador, porém sempre com seriedade e rigor; sendo de fácil compreensão entre os usuários, ou seja, consumidores, fiscais (Góes, 1999).

Além de difundir a legislação, os programas devem sensibilizar o profissional para a adoção de boas práticas operacionais na manipulação, preparo e comércio de alimentos mais seguros (Souza et al., 2003). As melhores formas para assegurar a qualida- 
de da alimentação servida são a educação e o treinamento constante dos manipuladores, pois criam um conjunto de meios e processos mediante os quais o indivíduo é ensinado e aperfeiçoado na execução de determinada tarefa, e atualmente os treinamentos para manipuladores vêm sendo elaborados tomando como base esse conceito (Oliveira et al., 2003).

Além dos cuidados com a higiene dos alimentos, dos utensílios e equipamentos, faz-se necessária uma atenção especial para a higiene do espaço onde se preparam e distribuem as refeições, pois o resultado final do alimento depende dessa corrente ser segura e nunca rompida. Nem sempre é possível um local perfeito para o serviço de alimentação. Mas pode ser adaptado, tornando-se ideal para o desenvolvimento de um excelente trabalho, sem riscos para o alimento (SESC, 2004; Resolução $n^{\circ}$ 275, 2002).

Embora o comércio de ambulantes esteja sujeito à regulamentação em países desenvolvidos, representa uma lacuna normativa em diversos países tropicais. No Brasil, não há legislação federal para a atividade. Ao mesmo tempo, com a implantação do Sistema Único de Saúde e a descentralização das suas ações, o controle sanitário desse segmento passou a ser responsabilidade dos municípios. Dessa forma, enquanto alguns municípios avançaram na elaboração de normas próprias, muitos sequer alcançaram a organização dos seus serviços de Vigilância Sanitária (Cardoso et al., 2003).

O decreto da Secretaria Municipal deAdministração e Negócios n ${ }^{\circ}$ 331, de 30 de novembro de 1992, do Gabinete do Prefeito de Ponta Grossa, de acordo com a Lei n ${ }^{\circ} 4736$ aprova o Regulamento do Comércio Ambulante (Brasil, 1992).

A Lei da Secretaria Municipal de Administração e Negócios Jurídicos n ${ }^{\circ}$ 4736, de 18 de maio de 1992, do Gabinete do Prefeito de Ponta Grossa, dispõe sobre o comércio ambulante do município, onde são estabelecidos critérios relacionados à licença para o exercício, seus deveres e penalidades em caso de infração (Brasil, 1992). A higiene no comércio ambulante de lanches e comestíveis em geral está disposta na Lei da Secretaria Municipal de Administração e Negócios $n^{\circ} 6640$, de 23 de novembro de 2000, do Gabinete do Prefeito de Ponta Grossa (Brasil, 2000).

O Ofício Municipal $n^{\circ}$ 139, de 17 de julho de 2002, da Gerência de Vigilância Sanitária, destaca que só poderão ser oferecidos ao consumo alimentos mantidos sob condições adequadas de conservação (Brasil, 2002).

Considerando-se que os vendedores de rua são comerciantes que fornecem rotineiramente alimentos para a população, urge buscar meios que garantam o seu acesso à informação, assegurando efetiva intervenção nos riscos inerentes ao consumo de alimentos de baixa qualidade higiênico-sanitária. AResolução n²16, de 15 de setembro de 2004, da Agência Nacional da Vigilância Sanitária, dispõe sobre o Regulamento Técnico de Boas Práticas para Serviços de Alimentação, incluindo os vendedores ambulantes de alimentos (Brasil, 2004). Um dos pontos importantes dessa normatização seria a obrigatoriedade de capacitação dos proprietários e manipuladores desses serviços.

\section{Metodologia}

Foram estudados 24 (vinte e quatro) pontos de venda de comercialização de alimentos por ambulantes na região central da cidade de Ponta Grossa, Estado do Paraná. Para investigação, delimitou-se o trecho que engloba o grande fluxo de pessoas.

Os pontos de venda foram avaliados através de análise visual e preenchimento da Ficha de Verificação (Anexo 1) elaborada segundo modelo da Resolução n ${ }^{0} 275$ (Brasil, 2002), da Vigilância Sanitária Municipal e Valente et al. (2003). Esses pontos foram analisados conforme as condições higiênico-sanitárias da infra-estrutura (área externa; área interna; piso; teto; paredes; portas, janelas e outras aberturas; iluminação; ventilação e climatização; abastecimento de água e esgotamento; higienização das instalações; manejo de resíduos e instalações sanitárias); condições higiênicosanitárias dos equipamentos, utensilios e manipuladores (vestuário; hábitos higiênicos; estado de saúde e programa de capacitação dos manipuladores e supervisão), e ainda produção do alimento (matéria-prima, ingredientes e embalagens; armazenamento e conservação; data de validade), considerando-se as normas de BPF apresentadas na Resolução $n^{0} 275$ (Brasil, 2002), Portaria n 326 (Brasil, 1997) e Resolução nº 216 (Brasil, 2004).

As entrevistas foram realizadas entre os meses de julho a agosto de 2004, e duraram em média vinte 
minutos, cada uma. Dos trinta e seis comerciantes de alimentos, instalados na área delimitada para este estudo, vinte e quatro (66,7\%) permitiram a análise de seu estabelecimento, através da ficha de verificação.

Para determinação dos resultados foram utilizados valores numéricos para os itens investigados, segundo metodologia de Valente et al. (2003), apresentados na Tabela 1. Foram considerados para tabulação dos dados os resultados "sim”, para a totalização dos itens investigados (100\%). Nos casos em que as conformidades não eram aplicadas (NA), levou-se em conta o número de itens que se aplicava a determinado ponto de venda.

Tabela 1 - Critério de classificação de acordo com a porcentagem de itens atendidos na ficha de verificação.

\begin{tabular}{c|c}
\hline Pontuação \% & Classificação \\
\hline $91-100$ & Excelente \\
\hline $76-90$ & Bom \\
\hline $51-75$ & Regular \\
\hline $20-50$ & Ruim \\
\hline $0-19$ & Péssimo \\
\hline
\end{tabular}

\section{Resultados e discussão}

Dentre os produtos comercializados, foram encontrados lanches (cachorro-quente, sanduíches e outros), salgados (coxinha, risólis, etc), pipoca, maçãdo-amor, cocada, espetinho de frutas com chocolate, churros, caldo-de-cana, refrigerante (em lata e em copo), sucos (em garrafa, comercializados), cerveja (em lata), café(em copo), bala, chicletes, doces e salgadinhos (em pacote, comercializados).

\subsection{Infra-estrutura}

No item "Infra-estrutura”, foram detectadas inadequações da área externa que delimitava os "carrinhos" ou "barracas", sendo que 91,6\% desses locais apresentaram problemas, tais como a presença de animais, acúmulo de lixo e entulho nas imediações. A área interna também demonstrou problemas, com 91,3\% dos locais contendo objetos em desuso no recinto. As estruturas das paredes, portas, janelas, teto, revestimento e piso das instalações apresentaram $63 \%$ de comprometimento: rachaduras, trincas e material de acabamento não apropriado a um local de comercialização de alimentos. Apesar de 75,0\% dos responsáveis pelas “barracas” garantirem uma higienização adequada e diária de suas instalações, em 60,7\% dos casos isso não foi confirmado pela análise visual.

O equipamento para retirada dos gases e vapores exigido pela Lei da Secretaria Municipal de Administração e Negócios n ${ }^{\circ}$ 6640, de 23 de novembro de 2000, do Gabinete do Prefeito de Ponta Grossa, não foi encontrado em nenhum dos locais visitados. Em 50,0\% desses mesmos locais, a iluminação natural ou artificial é adequada à atividade desenvolvida e apresenta bom estado de conservação.

O suprimento de água, quando presente (13,3\%), estava sendo feito pelo acondicionamento em galões da água proveniente das residências dos vendedores. Como não possuem canalização dos efluentes à rede de esgoto, cerca de 64,0\% dispunham de um reservatório próprio para esgotamento e armazenamento da água utilizada. Em 71,4\% das instalações, não havia pia para higienização e lavagem de utensílios, item este exigido pela Resolução n 216 do Ministério da Saúde (Brasil, 2004).

No tocante ao uso de instalações sanitárias, os ambulantes relataram o uso de dependências próximas, o que nem sempre pôde ser verificado, como no caso do comércio noturno, quando alguns comerciantes declararam utilizar instalações de casas de conhecidos próximos. Dentro desses parâmetros, apenas 9,0\% das instalações sanitárias apresentaram-se íntegras e dotadas de higienização e organização. Através de uma análise geral, as instalações sanitárias classificaram-se como “ruins” (25,0\%) e “péssimas” (75,0\%). Podese observar tais resultados através da apresentação da Figura 1. 


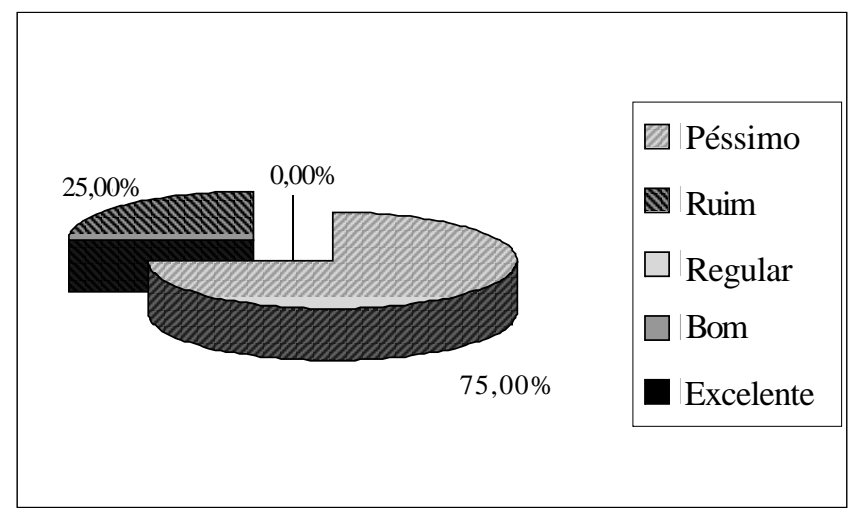

Figura 1 - Condições das instalações sanitárias

Os resíduos são tratados de forma imprópria. Nenhum ponto de venda possui em sua área interna lixeira com pedal. Amaioria utiliza sacolas plásticas sem suporte para acondicionamento. Na parte externa, as lixeiras estão presentes, porém sem proteção de saco plástico, mantendo-se sujas durante todo o expediente. Nenhum ponto de venda apresentou recipiente próprio para descarte de material reciclável. Ainda assim, $13,4 \%$ dos ambulantes garantem a retirada freqüente do lixo, enquanto os $86,6 \%$ restantes não o tratam de forma correta.

A localização das “barracas” que comercializam alimentos em vias públicas já constitui um dos pontos desfavoráveis para garantir a proteção dos alimentos contra a contaminação ambiental. A proximidade ao fluxo de veículos e de pessoas agrava essa situação, deixando os produtos expostos à poeira e poluição (Nascimento et al., 2004).

A Figura 2 apresenta as condições das infraestruturas dos ambulantes, segundo os conceitos determinados na metodologia.

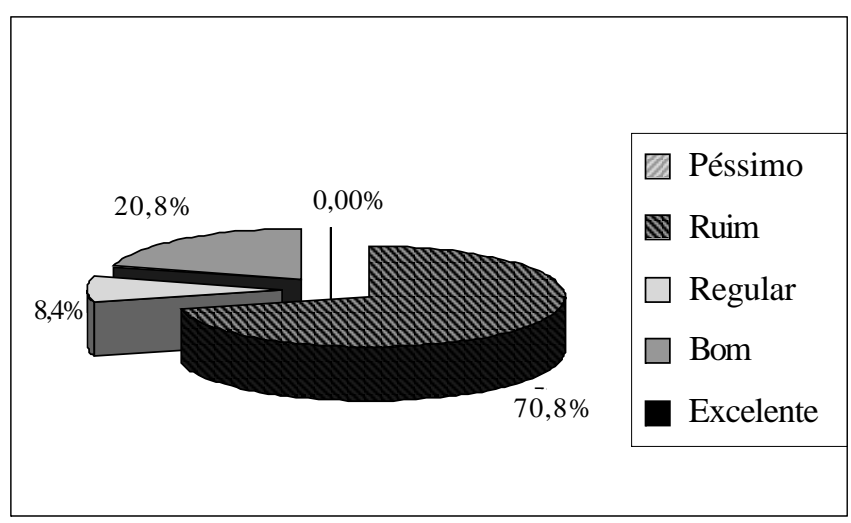

Figura 2 - Condições das infra-estruturas
Os pontos de venda foram classificados como estando em condições "ruins”" em 70,8\% dos locais visitados, "regulares” em 8,4\%, “péssimas” em 20,8\% do total de estabelecimentos avaliados. Nenhum deles obteve classificação excelente.

\subsection{Equipamentos e Utensílios}

Nesse item os resultados demonstraram que, apesar de 62,5\% apresentarem superfícies com material de fácil higienização e não contaminante, apenas 50,0\% estavam em bom estado de conservação, sendo que cerca de 40,0\% dos proprietários mantêm higienização constante. As falhas nos procedimentos de higienização de equipamentos e utensílios permitem que os resíduos aderidos aos equipamentos e superfícies se transformem em potencial fonte de contaminação cruzada (Chesca et al., 2003).

Os entrevistados, geralmente os proprietários, relataram levar utensílios no final do período de trabalho para serem lavados em casa, transportados de forma variada. Em 100\% dos locais os utensílios de uso dos consumidores eram descartáveis. A Figura 3 apresenta os resultados obtidos para o item Equipamentos e Utensílios, onde foi verificado que $45,8 \%$ dos pontos obteve avaliação “ruim”, 12,5\% "regular” e 41,7\% alcançaram uma avaliação "boa”. Não houve classificação “excelente”.

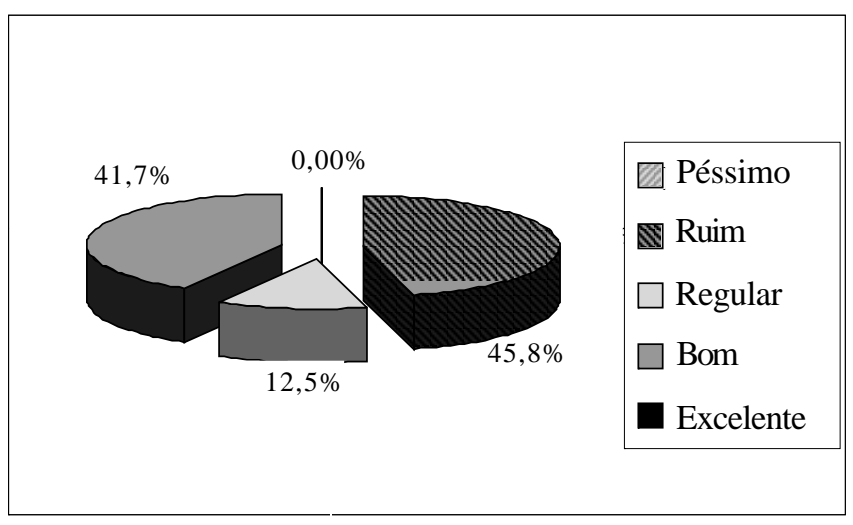

Figura 3 - Condições de equipamentos e utensílios

\subsection{Manipuladores}

Nesse item foram observados que $76,4 \%$ dos proprietários/manipuladores apresentavam-se sem uso de uniforme adequado, além de um asseio pessoal des- 
favorável (com utilização de adornos, esmalte, unhas compridas e falta de boa apresentação corporal). Quanto aos hábitos higiênicos, apenas 12,5\% dos manipuladores enquadram-se na faixa adequada, já que 87,5\% manipulam dinheiro com freqüência e não possuem um local apropriado para higienização das mãos. Em nenhum dos locais visitados houve conhecimento ou percepção visual de manipuladores trabalhando em estado de saúde que pudesse acarretar prejuízo à atividade, e todos eles afirmaram não receber orientação sobre higiene pessoal. Em relação a esse item, 70,8\% receberam classificação “ruim”; 16,7\% “péssimo"; 12,5\% "regular”. Com base nesses resultados, pôde-se chegar a um perfil dos manipuladores de alimento vendido nas ruas, conforme valores destacados na Figura 4. Segundo Lucca (2000), os manipuladores constituem uma das mais importantes fontes de contaminação dos alimentos, e a manipulação inadequada pode, não somente veicular microrganismos patogênicos, como também propiciar o desenvolvimento e a sobrevivência desses patógenos.

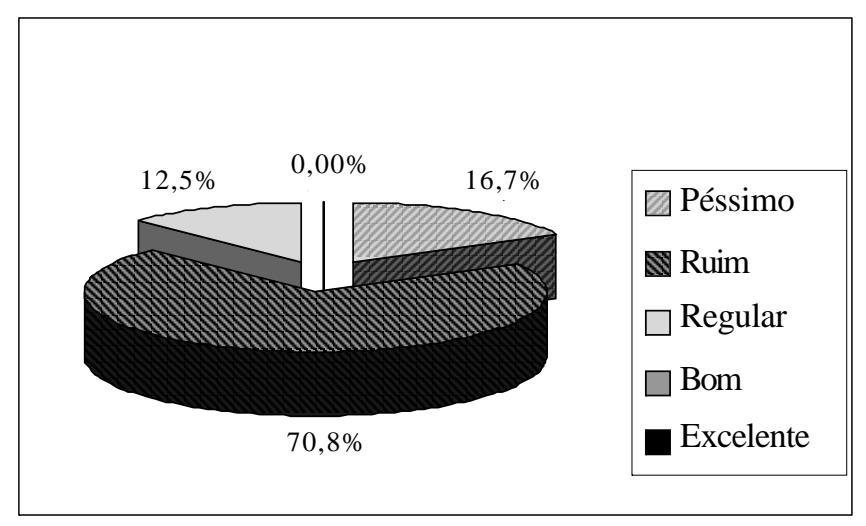

Figura 4 - Perfil dos manipuladores

\subsection{Produção do Alimento}

No item referente à Produção do Alimento (matéria-prima, ingredientes e embalagens; armazenamento e conservação do alimento), 79,9\% dos responsáveis garantiram adquirir carne inspecionada e matéria-prima de boa procedência, realizando suas compras diariamente, não mantendo nenhum estoque. Nascimento et al. (2004) destaca que a qualidade da matéria-prima utilizada na preparação dos alimentos é de fundamental importância para um produto final adequado, bem como o cumprimento dos procedimentos quando da espera dos produtos à venda, garantindo um alimento seguro ao consumidor.

Todos os pontos de venda utilizavam embalagens de material não reciclado, que entram em contato com o alimento. As bisnagas de maionese, catchup e mostarda ainda são bastante utilizadas por esse tipo de comércio. Constatou-se que cerca de 75,0\% dos comerciantes descartam ao final do dia os produtos remanescentes nas bisnagas; mas outros 10,0\% confessaram confeccionar artesanalmente a maionese e reutilizar a sobra das bisnagas.

A maionese pode ser contaminada durante a sua manipulação, devido à utilização de ovos crus, às contaminações cruzadas ou à manipulação inadequada por portadores assintomáticos. A Salmonella multiplica-se na maionese, principalmente quando esta é preparada com legumes, o que propicia o aumento do pH (Zoli et al., 2002).

Do mesmo modo, o gelo reciclável só foi encontrado em 9,0\% dos pontos de venda que utilizam essa matéria-prima. O restante utiliza gelo doméstico, sendo que $86,4 \%$ dos locais usam caixa isotérmica ou refrigerador, para conservação dos alimentos. A Lei da Secretaria Municipal de Administração e Negócios $n^{\circ}$ 6640, de 23 de novembro de 2000, do Gabinete do Prefeito de Ponta Grossa, proíbe o uso de gelo doméstico e recomenda a utilização de gelo tipo reciclável (BRASIL, 2000).

Por sua extrema perecibilidade, os produtos que transitam nesse tipo de comércio, como lanches e salgados preparados no ponto de venda, exigem refrigeração em ambiente e temperatura adequados. Caixas isotérmicas com gelo de procedência duvidosa podem vir a contaminar o alimento armazenado, assim como caixas de isopor danificadas e sujas. Nesses casos, a qualidade microbiológica é a mais afetada, pois produtos cárneos e vegetais podem constituir fonte de Escherichia coli, Salmonella sp., Shigella sp. e Listeria monocytogenes (Mendonça et al., 2002).

Nos locais que vendem salgados acondicionados em estufas, $100 \%$ desconheciam a temperatura ideal para a conservação dos alimentos. Os aquecimentos prolongados a temperaturas entre $15^{\circ} \mathrm{C}$ e $65^{\circ} \mathrm{C}$, sobretudo em instalações comunitárias, pode favorece a proliferação de C. perfringens (Sinell, 1981). Este resultado está em desacordo com o Ofício Municipal no 139, de 17 de julho de 2002, da Gerência de Vigilância Sanitária, segundo o qual só poderão ser oferecidos 
ao consumo alimentos mantidos sob condições adequadas de conservação (BRASIL, 2002).

Dos locais visitados, em $87,5 \%$, os produtos de higiene vinham sendo armazenados em locais distintos. A área para guardar objetos utilizados na higienização deve ser isolada dos produtos alimentícios. Silva Jr (2001) discute sobre o poder tóxico dos desinfetantes e anti-sépticos, que podem interferir na saúde do consumidor, quando ingeridos com os alimentos.

A Figura 5 apresenta as Condições da Produção de Alimentos, levando-se em conta os resultados relativos à matéria-prima, ingredientes e embalagens, armazenamento e conservação do alimento. Nota-se que $16,6 \%$ dos estabelecimentos classificaram-se no nível "bom". O restante dos estabelecimentos dividiram-se em 41\% com classificação “ruim” e 41,7\% com "regular".

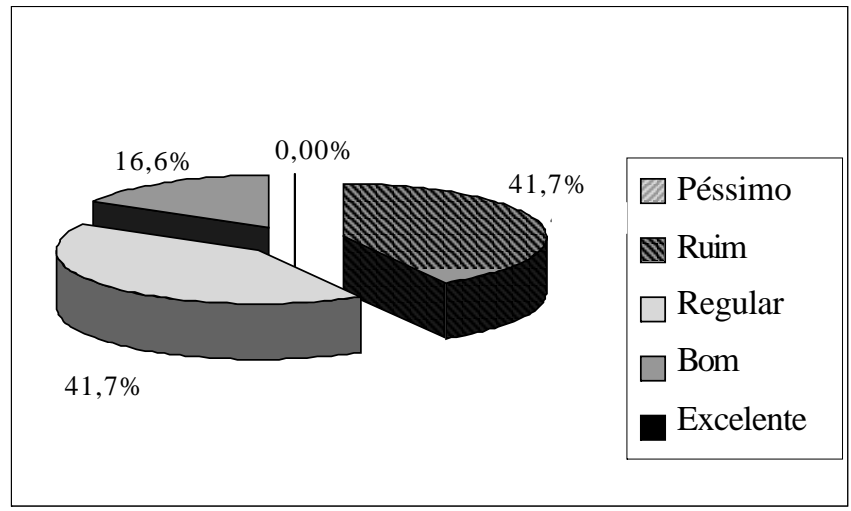

Figura 5 - Condições de produção de alimentos

\subsection{Condições Higiênico-Sanitárias dos Pontos de Venda Estudados}

A Figura 6 demonstra os resultados referentes às condições gerais de todos os pontos de venda avaliados, levando-se em conta todos os itens da ficha de verificação.

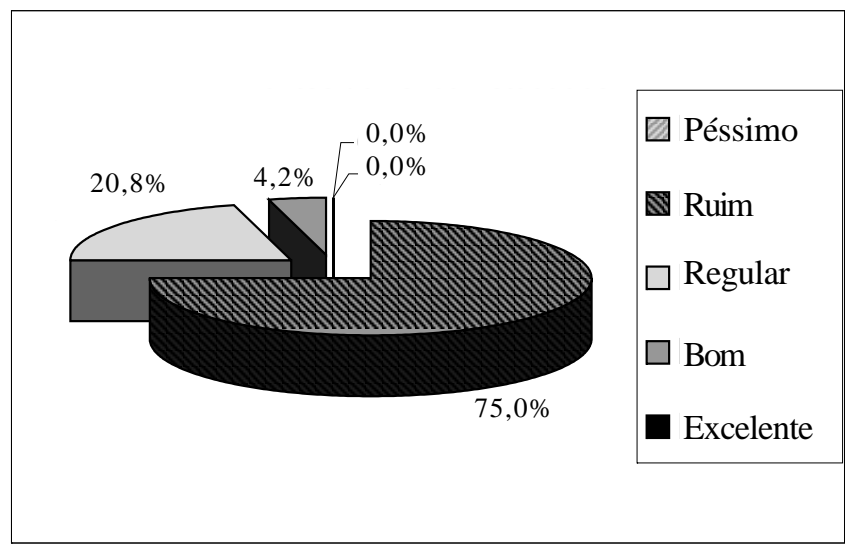

Figura 6 - Condições higiênico-sanitárias dos pontos de venda estudados

Pode-se observar que somente $4,2 \%$ (o que equivale a apenas um ponto de venda) receberam uma classificação de nível “bom”, atendendo a 79,0\% dos itens da ficha de verificação. Cinco pontos de venda20,8\% - foram classificados como "regulares”, uma vez que atenderam de $51,0 \%$ até $59,2 \%$ dos itens da ficha de verificação. Com amostragem relevante, figuram os demais (dezoito) pontos de venda (75,0\%), que atenderam entre $21,6 \%$ a $50,0 \%$ dos itens estabelecidos na ficha, recebendo conseqüentemente uma classificação "ruim”. A pontuação foi nula para locais classificados como “excelente” e "péssimo”.

A Tabela 2 mostra as condições gerais apresentadas pelos pontos de venda, conforme o produto vendido. 
Tabela 2 - Condições gerais dos locais visitados conforme o tipo de produtos vendidos

\begin{tabular}{cccc}
\hline $\begin{array}{c}\text { Tipos de Produtos } \\
\text { Vendidos* }\end{array}$ & Ruim\% & Regular\% & Bom\% \\
\hline Classe 1 & $31,9 \%$ & $10,6 \%$ & $2,1 \%$ \\
Classe 2 & $17,1 \%$ & - & - \\
Classe 3 & $27,7 \%$ & $10,6 \%$ & - \\
\hline
\end{tabular}

* Classe 1: preparação no local de lanches ou salgados; Classe 2: preparação no local de doces como "churros" e espetinhos de frutas; Classe 3: venda de produtos pré-processados, como doces, salgadinhos.

Os pontos de venda com maior manipulação, com preparação no local de lanches e salgados, 31,9\% apresentaram classificação ruim e 10,6\%, classificação regular. Vale ressaltar que nesses locais eram armazenados e manipulados alimentos perecíveis, como queijo, presunto e carnes.

Esses resultados vêm ao encontro de outros trabalhos que verificam a inadequação das condições higiênico-sanitárias na venda de alimentos na rua, em diferentes cidades do Brasil (Mendonça et al, 2002; Nascimento et al., 2004). A deficiente informação e falta de educação sanitária de consumidores e comerciantes podem ser sentidas, não existindo real consciência dos riscos potenciais que essas práticas podem acarretar à saúde da população (Mendonça et al., 2002).

A busca da garantia da segurança e qualidade dos produtos e da prestação de serviços na área de alimentos constitui instrumento básico na preservação de atributos relacionados com o valor nutricional e com os critérios de qualidade sanitária dos alimentos na prestação de serviços nesse âmbito, com vistas à proteção da saúde do consumidor, dentro da perspectiva do direito humano à alimentação e nutrição adequadas (CGPAN, 2000).

Desta forma, o desafio do Poder Público, particularmente o municipal, é conciliar os interesses dos que recorrem às atividades informais como alternativa de ocupação e a necessidade de garantir a utilização coletiva dos espaços públicos (Goes, 1999).

\section{Conclusão}

Os resultados obtidos com o presente estudo levam às seguintes conclusões:

- Os pontos de venda não possuem infraestrutura básica;

- A higienização dos equipamentos e utensílios é precária, ensejando risco de contaminação;

- Os vendedores desconhecem as técnicas adequadas de manipulação, bem como procedimentos para assegurar a inocuidade dos alimentos;

- Os alimentos recebem um tratamento razoável, porém com significativo risco em tratamentos posteriores, sobretudo na conservação de alimentos preparados.

Ações para o controle de qualidade de alimentos tornam-se necessárias, dentre as quais se destacam o treinamento e a reciclagem periódica dos profissionais envolvidos na produção de alimentos e monitoramento das condições dos manipuladores.

Sugere-se a adoção de medidas que contribuam para a execução de trabalhos educativos, junto a vendedores e comerciantes, de modo a minimizar os erros e riscos identificados neste estudo.

\section{REFERÊNCIAS}

1.BRASIL, 1992. Decreto da Secretaria Municipal de Administração e Negócios no 331, de 30 de novembro de 1992, do Gabinete do Prefeito de Ponta Grossa. Aprova o Regulamento do Comércio Ambulante.

2. BRASIL, 1992. Lei da Secretaria Municipal de Administração e Negócios Jurídicos no 4736, de 18 de maio de 1992, do Gabinete do Prefeito de Ponta Grossa. Dispõe sobre o comércio ambulante de Ponta Grossa, estabelecendo critérios relacionados à licença para o exercício, seus deveres e penalidades em caso de infração.

3. BRASIL, 1997. Portaria SVS/MS n 326, de 30 de julho de 1997. Estabelece a necessidade do constante aperfeiçoamento das ações de controle sanitário na área de alimentos, visando a proteção da saúde da população. D.O.U. de 01/08/1997.

4. BRASIL, 2000. Lei da Secretaria Municipal de Administração e Negócios nº 6640, de 23 de novembro de 2000, do Gabinete do Prefeito de Ponta Grossa. Dispõe sobre a higiene no comércio ambulante de lanches e comestíveis em geral.

5. BRASIL, 2002. Ofício Municipal no 139 de 17 de julho de 2002 da Gerência de Vigilância Sanitária. Determina normas técnicas estipuladas a todos os vendedores do comércio ambulante. 
6. BRASIL, 2002. Resolução RDC n ${ }^{\circ} 275$, de 21 de outubro de 2002. Dispõe sobre o Regulamento Técnico de Procedimentos Operacionais Padronizados e aplicados aos Estabelecimentos Produtores/Industrializadores de Alimentos e a Lista de Verificação das Boas Práticas de Fabricação em Estabelecimentos Produtores/Industrializadores de Alimentos. D.O.U. de 06/11/2002.

7. BRASIL, 2004. Resolução RDC nº 216, de 15 de setembro de 2004. Dispõe sobre o Regulamento Técnico de Boas Práticas para Serviços de Alimentação. D.O.U. de 16/09/2004.

8. BRITO, G.; CORDEIRO, L. N.; JOSINO, S. A.; MELO, M. L. de; COUTINHO, H. D. M. Avaliação da Qualidade Microbiológica de Hambúrgueres e Cachorros-quentes Comercializados por Vendedores Ambulantes no Município de Juazeiro do Norte, CE. Revista Higiene Alimentar, v. 17, $\mathrm{n}^{\circ}$ 110, p.90-94, julho 2003.

9. CÂMARA, S. A. V. Surtos de Toxinfecções Alimentares no Estado de Mato Grosso do Sul, no período de 1998-2001. Mato Grosso do Sul, 2002, 79 páginas. Dissertação (Monografia em Gestão em Saúde). Escola de Saúde Pública, Campo Grande/ MS.

10. CARDOSO, R. C. V.; LOUREIRO, E. S.; NEVES, D. C. S.; SANTOS, H. T. C. Comida de Rua: um espaço para estudo na Universidade Federal da Bahia. Revista Higiene Alimentar, v. 17, no 111, p.12-17, agosto 2003.

11. CGPAN - Coordenação Geral da Política de Alimentação e Nutrição, 2000. Garantia da Segurança e da Qualidade dos produtos e da prestação de serviços na área de alimentos. Disponível em <http://www.portal.saude.gov.br> acesso em 04-jul-2004.

12. CHAVES J. B. P. Controle de Qualidade. Disponível em $<$ http://www.dta.ufv.br/artigos/appcc.htm> acesso em 24-jul2004.

13. CHESCA, A. C.; MOREIRA, P. A.; ANDRADE, S. C. B. J. de; MARTINELLI, T. M. Equipamentos e utensílios de unidades de alimentação e nutrição: um risco constante de contaminação das refeições. Revista Higiene Alimentar, v. 17, no 114/115, p.20-23, nov/dez 2003.

14. FRANCO, B. D. G. de M.; LANDGRAF, M. Microrganismos Patogênicos de Importância em Alimentos, in: FRANCO, B. D. G. de M.; LANDGRAF, M. Microbiologia dos Alimentos. São Paulo: Atheneu, 2002, p.33-71. FRANCO, B. D. G. de M.; LANDGRAF, M. Microrganismos Patogênicos de Importância em Alimentos, in: FRANCO, B. D. G. de M.; LANDGRAF, M. Microbiologia dos Alimentos. São Paulo: Atheneu, 2002, p.3371.

15. FIGUEIREDO, R. M. Higiene dos alimentos. Como não comer fungos, bactérias e outros bichos que fazem mal. Disponível em <http://www.higienedosalimentos.com.br/ dva.asp $>$ acesso em 18-jul-2004.

16. FORSYTHE, S. J. Microbiologia da Segurança Alimentar. Porto Alegre: Artmed, 2002, p.424.
17. GÓES, J.A. W. Consumo de Alimentos de Rua em Salvador: o que é que a baiana/(o) tem?. Bahia Análise e Dados. Salvador/ BA, v. 9, nº 2, p.89-92, setembro 1999.

18. HANASHIRO, A.; MORITA, M.; TORRES, E. A. F. S.; MATTÉ, M. H. 2002. Qualidade Higiênico-Sanitária de Alimentos de Rua-Populares Versus OrientaisComercializados em São Paulo. Disponível em $<$ www.revnetdta.com> acesso em 31-ago-2004.

19. LUCCAA. 2000. Alimentos Vendidos nas Ruas. Disponível em <http://www.saudenainternet.com.br/especial/ especial_16.shtml> acesso em 23-ago-2004.

20. MENDONÇA, S. C.; CORREIA, R. T. P.; ALBINO, E. Condições Higiênico-Sanitárias de Mercados e Feiras Livres da Cidade de Recife-PE. Revista Higiene Alimentar, v. 16, $n^{\circ}$ 94, p.20-25, março 2002.

21. NASCIMENTO, A. J. P.; GERMANO, P. M. L.; GERMANO, M. I. S. Comércio Ambulante de Alimentos: Avaliação das Condições Higiênico-Sanitárias na Região Central de São Paulo, SP. Revista Higiene Alimentar, v. 18, nº 123, p.42-48, agosto 2004.

22. OLIVEIRA, A. de M.; GONÇALVES, M. O.; SHINOHARA, N. K. S.; STAMFORD, T. L. M. Manipuladores de Alimentos: um fator de risco. Revista Higiene Alimentar, v. 17, $n^{\circ}$ 114/115, p.12-18, nov/dez 2003.

23. PINTO, A. D. M. 1996. Doenças de Origem Microbiana Transmitidas pelos Alimentos. Disponível em <http:// www.ipv.pt/millenium/ect4_1.htm> acesso em 08-jul-2004.

24. RICHARDS, N. S. P. S. Segurança Alimentar: como prevenir contaminações na indústria. Revista Food Ingradients, $n^{\circ} 18$, p.16-30, mai/jun 2002.

25. RODRIGUES, K. L.; GOMES, J. P.; CONCEIÇÃO, R. C. S. da; BROD, C. S.; CARVALHAL, J. B.; ALEIXO, J. A. G. Condições higiênico-sanitárias no Comércio Ambulante de Alimentos em Pelotas-RS. Revista Ciência e Tecnologia de Alimentos, Campinas, 23(3), p.447-452, set-dez 2003.

26. SESC - Serviço Social do Comércio. Higiene e Apresentação Pessoal dos Manipuladores de Alimentos. São Paulo, 2004.

27. SILVA JR, E. A. Manual de Controle Higiênico-Sanitário em Alimentos. $4^{\text {a }}$ ed. São Paulo: Varela, 2001, p.297-307.

28. SINELL, H. J. Introducción a la Higiene de los Alimentos. Espanha: Acribia, 1981, p. 13-36.

29. SOUZA, S. S. de; PELIOCINI, M. C. F.; PEREIRA, I. M. T. B. A Vigilância Sanitária de Alimentos como Instrumento de Promoção de Saúde: relato de experiência de educação em saúde para o comércio varejista de alimentos e construção de um projeto de parceria. Revista Higiene Alimentar, v. 17, $\mathrm{n}^{\circ}$ 113, p.33-37, outubro 2003.

30. VALENTE, D.; PASSOS, A. D. C. Avaliação Crítica da Ficha de Inspeção em Estabelecimentos da Área de Alimentos. 
Revista Higiene Alimentar, v. 17 n ${ }^{0}$ 111, p.37-48, agosto 2003.

31. ZOLI, J. A.; NEGRETE, I. R. A.; OLIVEIRA, T. C. R. M. Avaliação da Contaminação por Staphylococcus aureus e
Salmonella spp., de maionese de batata comercializada em Londrina, PR. Revista Higiene Alimentar, v. 16, nº 95, p.62-71, abril 2002.

\section{Anexo 1 - Ficha de Verificação}

\begin{tabular}{|c|c|c|c|}
\hline \multirow{2}{*}{\multicolumn{4}{|c|}{$\begin{array}{l}\mathrm{N}^{0} \text { da Ficha: } \\
\text { 1. Infra-estrutura }\end{array}$}} \\
\hline & & & \\
\hline \multicolumn{4}{|l|}{ 1.1. Área externa } \\
\hline \multicolumn{4}{|l|}{$\begin{array}{l}\text { 1.1.1. Área livre de focos de insalubridade. Ausência de acúmulo de lixo nas imediações, animais e } \\
\text { roedores na área externa e vizinhança (incluindo calçada e meio-fio). }\end{array}$} \\
\hline \multicolumn{4}{|l|}{ 1.1.2. Não deixar objetos em desuso ao redor do carrinho e trailer, como cadeiras, bacias, caixas, etc... } \\
\hline \multicolumn{4}{|l|}{ 1.2. Área interna } \\
\hline \multicolumn{4}{|l|}{ 1.2.1. Livre de objetos em desuso ou estranhos ao ambiente. } \\
\hline \multicolumn{4}{|l|}{ 1.3. Piso } \\
\hline \multicolumn{4}{|l|}{$\begin{array}{l}\text { 1.3.1. Material liso, resistente, impermeável, de fácil limpeza e em bom estado de conservação (livre } \\
\text { de defeitos, rachaduras, trincas, buracos e outros). }\end{array}$} \\
\hline \multicolumn{4}{|l|}{ 1.3.2. Em perfeitas condições de limpeza. } \\
\hline \multicolumn{4}{|l|}{ 1.4. Tetos } \\
\hline \multicolumn{4}{|l|}{$\begin{array}{l}\text { 1.4.1. Acabamento liso, em cor clara, impermeável, de fácil limpeza e em adequado estado de } \\
\text { conservação (livre de trincas, rachaduras, umidade, bolor, descascamentos e outros). }\end{array}$} \\
\hline \multicolumn{4}{|l|}{ 1.4.2. Em perfeitas condições de limpeza. } \\
\hline \multicolumn{4}{|l|}{$\begin{array}{l}\text { 1.4.3. O local de comercialização deverá ser coberto de modo a proteger o alimento dos raios solares, } \\
\text { poeira, chuva e outras formas de contaminação. Sendo para sanduíches, espetinhos e outros produtos: } \\
\text { local tipo trailer e veículo automotor ou carrinho móvel estando adaptado ao tipo de trailer. Para } \\
\text { cachorro quente e salgados: carrinho móvel. }\end{array}$} \\
\hline \multicolumn{4}{|l|}{ 1.5. Paredes } \\
\hline \multicolumn{4}{|l|}{$\begin{array}{l}\text { 1.5.1. Os carrinhos deverão ter superfícies lisas, impermeáveis, devidamente higienizadas e } \\
\text { desinfetadas. }\end{array}$} \\
\hline \multicolumn{4}{|l|}{ 1.5.2. Em perfeitas condições de limpeza. } \\
\hline \multicolumn{4}{|l|}{ 1.6. Portas, janelas e outras aberturas } \\
\hline \multicolumn{4}{|l|}{$\begin{array}{l}\text { 1.6.1. Com superfície lisa, fácil limpeza, em bom estado de conservação (ajustados aos batentes, sem } \\
\text { falhas de revestimento). }\end{array}$} \\
\hline \multicolumn{4}{|l|}{ 1.6.2. Existência de proteção contra insetos e roedores. } \\
\hline \multicolumn{4}{|l|}{ 1.6.3. Em perfeitas condições de limpeza. } \\
\hline \multicolumn{4}{|l|}{ 1.7. Iluminação } \\
\hline \multicolumn{4}{|l|}{ 1.7.1. Natural ou artificial adequada à atividade desenvolvida. } \\
\hline \multicolumn{4}{|l|}{ 1.7.2. Luminárias limpas e em bom estado de conservação. } \\
\hline \multicolumn{4}{|l|}{ 1.8. Ventilação e climatização } \\
\hline \multicolumn{4}{|l|}{ 1.8.1. Equipamento para retirada de gases e vapores. } \\
\hline \multicolumn{4}{|l|}{ 1.9. Abastecimento de água e esgotamento } \\
\hline 1.9.1. Reservatório de água com pelo menos $50 \mathrm{~L}$. & & & \\
\hline 1.9.2. Canalização dos efluentes à rede de esgoto ou reservatório próprio. & & & \\
\hline 1.10. Higienização das instalações & & & \\
\hline 1.10.1. Freqüência de higienização das instalações adequada (diária). & & & \\
\hline 1.10.2. Pia para higienização e lavagem de utensílios. & & & \\
\hline 1.11. Manejo dos resíduos & & & \\
\hline $\begin{array}{l}\text { 1.11.1. Lixo no interior do estabelecimento acondicionados em sacos de lixo apropriado, em } \\
\text { recipientes tampados de acondicionamento não manual, limpos, de fácil transporte e higienizados } \\
\text { constantemente. }\end{array}$ & & & \\
\hline $\begin{array}{l}\text { 1.11.2. Lixo externo de tamanho apropriado (não muito grande) para que o lixo não fique acumulado } \\
\text { por muito tempo, com saco de lixo apropriado e higienizado } \\
\text { constantemente. }\end{array}$ & & & \\
\hline 1.11.3. Retirada freqüente dos resíduos, evitando focos de contaminação. & & & \\
\hline 1.12. Instalações Sanitárias & & & \\
\hline 1.12.1. Instalações sanitárias com vasos sanitários, mictórios e lavatórios íntegros. & & & \\
\hline 1.12.2. Pisos e paredes adequadas e apresentando satisfatório estado de conservação. & & & \\
\hline $\begin{array}{l}\text { 1.12.3. Instalações sanitárias dotadas de produtos destinados à higiene pessoal: papel higiênico, } \\
\text { sabonete e toalhas de papel. }\end{array}$ & & & \\
\hline 1.12.4. Presença de lixeira com tampa. & & & \\
\hline 1.12.5. Local organizado e com higienização a & & & \\
\hline
\end{tabular}


2. Equipamentos e Utensílios

2.1. Equipamentos

2.1.1. Equipamentos dotados de superfície que seja de fácil higienização, de material não contaminante.

2.1.2. Em bom estado de conservação e funcionamento.

2.1.3. Em perfeitas condições de limpeza.

2.2. Utensílios

2.2.1. Manter utensílios como talheres, guardanapos e outros, acondicionados em embalagens plásticas fechadas.

2.2.2. Os utensílios de uso dos consumidores devem ser descartáveis.

2.2.3. Utensílios em material não contaminante, de tamanho e forma que permitam fácil higienização.

Em bom estado de conservação.

2.2.4. Em perfeitas condições de limpeza.

\section{Manipuladores}

\subsection{Vestuário}

3.1.1. Uniforme completo: calça, guarda-pó e touca, confeccionados em tecido de cor clara, preferencialmente branca.

3.1.2. Limpos e em adequado estado de conservação.

3.1.3. Asseio pessoal: boa apresentação, mãos limpas e unhas curtas, sem adornos, sem esmalte.

3.2. Hábitos higiênicos

3.2.1. Lavagem cuidadosa das mãos antes da manipulação de alimentos.

3.2.2. Manipuladores não espirram sobre os alimentos, não cospem, não tossem, não fumam, não manipulam dinheiro ou não praticam outros atos que possam contaminar o alimento.

\subsection{Estado de saúde}

3.3.1. Os manipuladores não poderão apresentar ferimentos e estado de saúde que possa acarretar prejuízos à atividade, tais como: tosse, diarréia, infecções respiratórias, etc...

3.4. Programa de capacitação dos manipuladores e supervisão

3.4.1. Existência de supervisão da higiene pessoal e manipulação dos alimentos (freqüência anual).

\section{Produção do alimento}

\subsection{Matéria-prima, ingredientes e embalagens}

4.1.1. Embalagens que entram em contato com o alimento não podem ser confeccionados com material reciclado.

4.1.2. Alimentos de origem animal deverão conter o registro do SIM.

4.1.3. Utilizar saches individuais de maionese, catchup e mostarda, sendo proibido o uso de bisnagas.

4.1.4. Toda e qualquer matéria-prima utilizada deve ser certificada de que não seja de procedência duvidosa.

\subsection{Armazenamento e conservação}

4.2.1. Os alimentos deverão ser armazenados, transportados, expostos à venda ou consumo de modo seguro, separados dos produtos sanitários, drogas veterinárias, agrotóxicos e afins. Só poderão ser oferecidos ao consumo de alimentos mantidos sob condições adequadas de conservação.

4.2.2. Os alimentos perecíveis devem ser acondicionados em equipamentos de conservação por temperatura, limpos e higienizados. Não é permitido o uso de caixa de isopor. A caixa isotérmica deve ser de material liso, impermeável e resistente.

4.2.3. O gelo utilizado deverá ser do tipo reciclável, sendo proibido o uso de gelo doméstico. 4.2.4. Os salgadinhos deverão estar acondicionados em estufa limpa e em temperatura de $65^{\circ} \mathrm{C}$.

\subsection{Data de validade}

4.3.1. Controle da validade dos alimentos, alimentos dentro do prazo de validade.

* Não se aplica

$N^{\circ}$ da Ficha:

Empresa:

Endereço:

Alvará/Licença Sanitária: ( ) Sim ( ) Não

Categoria de produtos:

Responsável legal/Proprietário do estabelecimento: 